Nig. J. Pure \& Appl. Sci. Vol. 33 (Issue 1, 2020)
eISSN 2756-4045
Life Sciences, Univ. of Ilorin, Nigeria
www.njpas.com.ng

doi: http://dx.doi.org/10.48198/NJPAS/20.A09

\title{
Comparative Widal Reaction for IgG/IgM Complement C3, lymphocyte and Neutrophils Assay in Patients with Suspected Typhoid Fever in Selected Hospitals in Kaduna State, \\ Nigeria
}

*Ella, E. E., Tijjani, S. and Aminu, M

Department of Microbiology, Ahmadu Bello University, Zaria, Kaduna State

\begin{abstract}
Typhoid also known as enteric fever is endemic in Nigeria most often diagnosed by the widal reaction though the results of this test are being questioned in many quarters. This has necessitated the search for other methods for analysis. This work is aimed at comparing the widal reaction with the rapid immunochromatographic assay the complement $\mathrm{C} 3$ and selected haematological indices. Two $\mathrm{ml}$ of blood was collected from 350 patients with suspected typhoid infection and analysed by the widal slide agglutination reaction and the $\operatorname{IgG/IgM~}$ Immunochromatographic assay. Complement $\mathrm{C} 3$ was assayed by ELISA while neutrophils and Lymphocyte counts were also performed. The finding showed that $41(11.7 \%)$ and $29(8.3 \%)$ were positive for S. typhi IgG and IgM respectively out of 350 patients. It was found that 207 patients had O-antigen widal reaction titres $1 / 80$ and above for S. typhi out of which, 30 (14.5\%) and 22(22.6\%) were IgG and IgM positive respectively. Those with reactions $1 / 80$ and above to the H-antigen were 118 with $24(20.3 \%)$ cases of $\operatorname{IgG}$ and $13(11.0 \%)$ of $\operatorname{IgM}$. The mean neutrophil and lymphocyte count in the IgM positive were $48.90 \pm 20.060$ and $60.28 \pm 17.64$ as compared to the negatives (48.46 \pm 18.95 and $55.02 \pm 19.19$ respectively). The mean neutrophil and lymphocyte count of $\operatorname{IgG}$ positive were $50.68 \pm 19.65$ and $57.22 \pm 19.72$ ) while the negatives were $48.20 \pm 1.08$ and $55.23 \pm 19.04$. the mean plasma levels of complement factors $\mathrm{C} 3$ in the IgG positive was $630.70 \pm 327.41$ as compared to those that are negative (626.97 \pm 247.72$)$. The complement $\mathrm{C} 3$ levels was significantly higher ( $\mathrm{P}$ $=0.000$ ) in the IgM positive ( $816.45 \pm 406)$ as compared to the IgM negatives (610.33 \pm 233.40$)$. No significant association was observed between the clinical features and the typhoid positives.
\end{abstract}

Keywords: Typhoid Fever, Widal test, Immunochromatographic test, Complement 3, IgG, IgM

\section{Introduction}

Typhoid also known as enteric fever is a caused by a highly virulent Salmonella typhi which is also very invasive. The illness is frequently encountered in tropical countries like Nigeria where it constitutes a serious source of morbidities and mortalities (Ibekwe, et al., 2008). Typhoid carriers are of special concern from a public health point of view because they are sources for the spread of diseases (WHO, 2003). Studies to immune response against these microorganisms are still evolving (Mashi, 2001). However, it has previously been shown that circulating 
immunoglobulins secreted by lymphocytes, are substantially sought to understand the host immune response elicited in Salmonella infection, however, events related elevated in the peripheral blood of adults with typhoid and paratyphoid fever and this

Page | 3619 increase can be used as both sensitive and specific diagnostic assay to identify patients with enteric fever (Sheikh, et al., 2009). These activated lymphocytes may represent cells activated early in infection either at mucosal surface or systematic sites.

Diagnosis of typhoid fever is essentially based on Widal Agglutination reaction (Elderman and Levine, 1986; Onuigbo, 1990; Mbuh, et al., 2003). However, this test has numerous setbacks such as poor specificity (Passey, 1995; Wain, et al., 2008). This necessitates the importance of a reliable, rapid diagnostic procedure for typhoid fever.New typhoid rapid antibody tests have been developed and evaluated in Asia and other developing countries, where typhoid is highly endemic and these assay kit are now commercially available Crump, et al., 2004; Ochiai, et al., 2008).

However, rapid typhoid tests are yet received enough attention to make them commercially available in Nigeria. To a large extent, studies on typhoid infection and the role of complement activation been exploited.

Also, biochemical and haematological changes have been associated with typhoid fever. Olubuyide et al. (1989) reported an elevation of Creactive proteins thus suggesting that the increase could be used as a diagnostic parameter for typhoid fever. The aim of this research is therefore to determine the importance of some specific and non-specific immune responses in patients presenting with symptoms characteristic of typhoid fever recruited from selected hospitals within Zaria metropolis, Kaduna, Nigeria.

\section{Materials and Methods \\ Study Area and Population}

The study recruited patients from selected hospital in Zaria, a city in Kaduna State in Northern Nigeria covering $300 \mathrm{~km}^{3}$. It is made up of two local Government Area, Zaria city and Sabon Gari local Government with 12 districts and a popupation of 408,198 people with an annual growth rate of $3.3 \%$ (NPC, 2013).

The selected hospitals used were Hajia Gambo Sawaba Hospital located in Zaria city area, Major Ibrahim Memorial Hospital located in Sabon gari local Government and Ahmadu Bello University Health Services, Sickbay, Samaru. The patients who attended the hospitals with symptoms characteristic of typhoid fever and who consented to the study were recruited.

\section{Study design, Inclusion and Exclusion Criteria}

The study was hospital based, cross sectional and experimental study carried out over a period of six months. Clinical samples were collected with the assistance of a trained medical personnel. Similarly, a structured questionnaire was administered of the patients that fulfilled the criteria for typhoid fever to obtain socio-demographic data before collection of samples. Ethical approval (MOH/ADM /744/VOL.1) was obtained from the ethical committee of the Kaduna State Ministry of Health prior to sample collection and commencement of the Research. A written consent was solicited and obtained from patients and those who gave their approval were included in the studies.

\section{Sample Size determination and collection}

The sample size was calculated using the formula by Naing et al. (2006) and a prevalence of $46 \%$ (Adabara et al., 2012).

$$
\begin{aligned}
& \mathrm{N}=\mathrm{Z}^{2} \mathrm{pq} / \mathrm{d}^{2} \\
& \mathrm{~N}=(1.96)^{2} \times 46 \times 1-0.05 / 0.05^{2} \\
& =3.841 \times 0.45 \times 0.5 / 0.0025=345.744 .
\end{aligned}
$$

Therefore, 350 samples were collected, for the sake of this study. A total of $3 \mathrm{mls}$ of blood samples was collected by the laboratory personnel using sterile five milliliters syringe aseptically by venous 
puncture. The blood was dispensed into EDTA containers and transported on ice in an insulated cold box to the Bacteriology Laboratory of Microbiology Department, ABU, where they were centrifuged at $1500 \mathrm{rpm}$. The plasma was

Page | 3620 transferred into sterile screwed cap bottles and stored at $-20^{\circ} \mathrm{C}$ until analysis.

\section{Detection of typhoid fever using the widal agglutination reaction}

Samples were screened for typhoid fever using the Widal kit (Lab care diagnostic, India) as instructed in the Manufacturers specifications. One drop $(0.1 \mathrm{ml})$ of undiluted plasma was added to circles on clean glass slides using a Pasteur pipette. Then, a drop $S$. typhi and S. papatyphi $\mathrm{H}$ and $\mathrm{O}$ antigens, the positive as well as the negative control were dispensed to their respective cycles. The antigen was mixed together with the plasma using separate Pasteur pipettes to fill whole of the individual circle. Then the slides were observed for agglutination.

\section{Detection of the Typhoid IgG and IgM using Immunochromatographic Assay Kit}

All the samples were tested for the typhoid IgM and IgG using Sensitive Salmonella typhi IgG/IgM Rapid test kit (Ubio Biotechnology, India) based on the Manufacturer's instruction. The test card was taken out from the foil porch and was placed on a horizontal surface, $5 \mathrm{ul}$ of plasma of patients was added to the sample well labeled $\mathrm{S}$, when the sample was fully absorbed, 2 drops of the diluents provided with the assay was added to the sample hole, after $15 \mathrm{mins}$, the results was read.

\section{Detection of the Complement C3 levels using ELISA}

Typhoid positive samples were screened for C3 using Human complement C3 ELISA based on Manufacturer's (Assaypro Human Complement C3 ELISA) Instruction. All samples and reagents were removed from the refrigerator and allowed to come to room temperature $\left(25^{\circ} \mathrm{C}\right)$. The coated strips were placed in a holder and labeled (one blank well, seven controls, two calibrators and 91 wells for sample specimens). About $3 \mathrm{ul}$ of the test samples, seven control and calibrators were added to $240 \mathrm{ul}$ of the serum diluents and mixed well to make 1 in 80 dilutions. Hundred microlitre (100ul) each of the diluted samples was dispensed into appropriate wells, ensuring that there were no air bubbles. Air bubbles present in the liquid were removed by tapping the holder. Hundred microlitre (100ul) of the serum diluents was added into the reagent blank well. The wells were incubated at room temperature $25^{\circ} \mathrm{C}$ for 30 minutes. After incubation, liquid from all wells was removed by washing three times with $300 \mathrm{ul}$ of the wash buffer. Hundred microlitre (100ul) of enzyme conjugate was added into each well and incubation was repeated for another 30 mins at room temperature $\left(25^{\circ} \mathrm{C}\right)$. Excess enzyme conjugate was removed by washing three times with the wash buffer. Hundred microlitre (100ul) of chromogen/substrate solution (TMB) was dispensed into each well and incubated again as before for 15 mins. Finally, 100ul of stop solution $\left(1 \mathrm{M} \mathrm{H}_{2} \mathrm{SO}_{4}\right)$ was added and the plate was tapped gently to mix contents of the wells. The reading was done using ELISA microplate reader (GF-M300 Microplate reader, B BRAN Scientific \$ Instrument, Company England) at 450nm.

\section{Determination of Percentage neutrophils and lymphocyte population}

Typhoid positives samples were determined for the neutrophils/lymphocyte's levels using staining technique (Cheesbrough 2006). A drop of blood was placed on the end of a clean dry slide, was smeared to give a thin film and allowed to air-dry. The film was fixed in methanol for 2 mins, then the slide was placed on a staining jar, $10 \%$ of the Giemsa stain was added, the slide was allowed to stay for $45 \mathrm{mins}$, then the stain was washed away rapidly with water. When dried, oil immersion was added and it was viewed under microscope using $\mathrm{x}$ 100 objective lens. 


\section{Data Analysis}

The data obtained were analysed with SPSS (statistical package for social sciences) version 20.0 software program. Pearson's chi square $\chi^{2}$ was Page | 3621 employed to determine association of variables set at a significance of at $95 \%$ confidence interval and $\mathrm{P}<0.05$ was considered significant. Means of parametric variables were analyzed using Student $t$ tests.

\section{Results}

The finding showed that $207(59.1 \%)$ and 118 (31.7\%) patients had titres above 80 to the $\mathrm{O}$ and $\mathrm{H}$ antigens of S. typhi be the widal reaction. Similarly, $153(43.7 \%)$ and $124(38.3 \%)$ reacted to the $\mathrm{O}$ and $\mathrm{H}$ antigens of the combined S. paratyphi group (Table 1). The distribution of the S. typhi O antigen titre among the $\operatorname{IgG}$ and $\operatorname{IgM}$ positives is presented in table 2. Out of the 40 samples with $1 / 160$ agglutination titre, 5 were positive for $\mathrm{IgG}$ while 4 where IgM positive. Similarly, of the 167 demonstrating $1 / 80$ titre, 21 were $\operatorname{IgG}$ positive and 18 were IgM positive. On the other hand, 9 out of the 27 tested patients demonstrated 1/60 titre were IgG Typhoid positive and only 4 where $\operatorname{IgM}$ positives, and 15 were positive for $\operatorname{IgG}$ out of 91 demonstrating the $1 / 80$ titre while 9 were $\operatorname{IgM}$ positive. A significant association was established between the $\mathrm{H}$ antigen and the $\mathrm{IgG}$ but not with the IgM positives (table 3 ).
The mean neutrophil count in the IgM typhoid positives $(48.90 \pm 20.060)$ was slightly higher than those that are negative $(48.46 \pm 18.95)$ while the mean lymphocyte count was significantly higher in typhoid patients $(60.28 \pm 17.64)$ than the $\operatorname{IgM}$ negatives (55.02 \pm 19.19$)$. The mean neutrophils of the IgG typhoid positive $(50.68 \pm 19.65)$ was higher than the IgG negatives $(48.20 \pm 1.08)$ and a higher mean lymphocytes counts was also observed in the IgG positives (57.22 \pm 19.72$)$ as compared with the negatives (55.23 \pm 19.04$)$. No significant association was observed between the mean neutrophils/ lymphocytes count and IgM levels of Typhoid patients (Table 4).

The Complement $\mathrm{C} 3$ levels was significantly higher $(\mathrm{P}=0.000)$ in the $\operatorname{IgM}$ positive $(816.45 \pm 406)$ as compared to the IgM negatives $(610.33 \pm 233.40)$. There was no significant association $(\mathrm{P}>0.05)$ between the complement factor $\mathrm{C} 3$ and the Immunoglobulin IgG. There was an increase in the Complement C3 levels of the IgM positives. $(816.45 \pm 406)$ as compared to the $\operatorname{IgM}$ negatives $(610.33 \pm 233.40), \quad$ a significant association $(\mathrm{P}<0.05)$, was observed between the IgM positives and the complement $\mathrm{C} 3$ levels (Tables 5). The relationship between clinical features associated with typhoid fever and the corresponding IgG and IgM positives is presented in Table 6 . No significant association was observed between the clinical features and the typhoid positives.

Table 1: Distribution of the Individual Widal Titre against the Serotypes of Salmonella

\begin{tabular}{lccccccc}
\hline Serotype & Antigen & \multicolumn{5}{c}{ Agglutination Titre / Number positive (\%) } \\
\cline { 2 - 7 } & & $\mathbf{1 / 2 0}$ & $\mathbf{1 / 4 0}$ & $\leq \mathbf{4 0}$ & $\mathbf{1 / 8 0}$ & $\mathbf{1 / 1 6 0}$ & $\geq \mathbf{8 0}$ \\
\hline S. typhi & $\mathrm{O}$ & 79 & 64 & 143 & 167 & 40 & 207 \\
& & $(22.6)$ & $(18.3)$ & $(40.9)$ & $(47.7)$ & $(11.4)$ & $(59.1)$ \\
S. typhi & $\mathrm{H}$ & 83 & 149 & 232 & 91 & 27 & 118 \\
& & $(23.7)$ & $(42.6)$ & $(66.3)$ & $(26.0)$ & $(7.7)$ & $(33.7)$ \\
S. paratyphi & $\mathrm{O}$ & 109 & 88 & 197 & 142 & 11 & 153 \\
& & $(31.1)$ & $(25.1)$ & $(56.2)$ & $(40.6)$ & $(3.1)$ & $(43.7)$ \\
S. paratyphi & $\mathrm{H}$ & 123 & 93 & 216 & 117 & 17 & 124 \\
& & $(35.1)$ & $(26.6)$ & $(61.7)$ & $(33.4)$ & $(4.9)$ & $(38.3)$ \\
\hline
\end{tabular}

$\mathrm{O}=$ Somatic antigen, $\mathrm{H}=$ Flagella antigen 
Table 2: Distribution of S. typhi $\mathrm{O}$ antigen and the corresponding IgG and IgM Positive Samples

\begin{tabular}{|c|c|c|c|c|c|c|c|}
\hline \multirow[b]{2}{*}{ O-antigen } & \multirow[b]{2}{*}{ No examined } & \multicolumn{3}{|c|}{ IgG } & \multicolumn{3}{|c|}{ IgM } \\
\hline & & $\begin{array}{c}\text { No positive } \\
(\%)\end{array}$ & $\chi^{2}$ & P-value & $\begin{array}{c}\text { No positive } \\
(\%)\end{array}$ & $\chi^{2}$ & P-value \\
\hline $1 / 20$ & 79 & $5(6.33)$ & 7.173 & 0.067 & $4(5.1)$ & 3.690 & 0.297 \\
\hline $1 / 40$ & 64 & $6(9.38)$ & & & $3(4.7)$ & & \\
\hline Sub total & 143 & 11(7.69) & & & $7(4.9)$ & & \\
\hline $1 / 60$ & 40 & $5(12.5)$ & & & $4(10.0)$ & & \\
\hline $1 / 80$ & 167 & $21(12.57)$ & & & $18(10.8)$ & & \\
\hline Sub total & 207 & $30(14.5)$ & & & $22(10.6)$ & & \\
\hline TOTAL & 350 & $41(11.7)$ & & & $29(8.3)$ & & \\
\hline
\end{tabular}

$\chi^{2}=$ Chi square, $\mathrm{P}>0.05$, No significant association.

Table 3: Distribution of the S. typhi $\mathrm{H}$ antigen and the corresponding IgG and IgM positive Samples

\begin{tabular}{|c|c|c|c|c|c|c|c|}
\hline \multirow[b]{2}{*}{ H-antigen } & \multirow[b]{2}{*}{ No examined } & \multicolumn{3}{|c|}{ IgG } & \multicolumn{3}{|c|}{ IgM } \\
\hline & & $\begin{array}{c}\text { No positive } \\
(\%)\end{array}$ & $\chi^{2}$ & P-value & $\begin{array}{c}\text { No positive } \\
(\%)\end{array}$ & $\chi^{2}$ & P-value \\
\hline $1 / 20$ & 83 & $5(6.0)$ & 18.1732 & $0.000^{*}$ & $5(6.0)$ & 2.541 & 0.468 \\
\hline $1 / 40$ & 149 & $12(8.1)$ & & & $11(7.4)$ & & \\
\hline Sub total & 232 & $17(7.3)$ & & & $16(6.9)$ & & \\
\hline $1 / 60$ & 27 & $9(33.3)$ & & & $4(14.8)$ & & \\
\hline $1 / 80$ & 91 & $15(16.5)$ & & & $9(9.9)$ & & \\
\hline Sub total & 118 & $24(20.3)$ & & & $13(11.0)$ & & \\
\hline TOTAL & 350 & 41 & & & 29 & & \\
\hline
\end{tabular}

Table 4: The mean neutrophils and lymphocyte count in relation to the $\operatorname{IgG}$ and $\operatorname{IgM}$ status of the study population

\begin{tabular}{lllllll}
\hline & \multicolumn{3}{c}{ IgG } & & \multicolumn{3}{c}{ IgM } \\
\hline \multirow{3}{*}{ Positive } & $\mathrm{N}$ & Neutrophils & Lymphocytes & $\mathrm{N}$ & Neutrophils & Lymphocytes \\
Negative & 41 & $50.68 \pm 19.65$ & $57.22 \pm 19.72$ & 21 & $49.90 \pm 20.6$ & $60.28 \pm 17.64$ \\
& 309 & $48.20 \pm 1.08$ & $55.23 \pm 19.04$ & 329 & $48.46 \pm 17.64$ & $55.02 \pm 19.19$ \\
& & & 350 & & \\
\hline
\end{tabular}


Table 5: The mean $\mathrm{C} 3$ levels ( $\mathrm{ug} / \mathrm{ml}$ ) in relation to $\mathrm{IgG}$ and $\mathrm{IgM}$ status of the study population

Page | 3623

\begin{tabular}{lcccc}
\hline & IgG & C3 & IgM & C3 \\
\hline Positive & 41 & $630.70 \pm 327.41$ & 29 & $816.45 \pm 406.0$ \\
Negative & 309 & $626.97 \pm 247.72$ & 329 & $610.33 \pm 233.40$ \\
P-value & & 0.931 & & $0.000^{*}$ \\
\hline
\end{tabular}

$(\mathrm{SD} \pm t$-test $)=$ Mean Standard Deviation, $t$-test, $\chi^{2}=$ Chi square, $\mathrm{P}=0.000^{*}$ Significant association $(\mathrm{P}<0.05)$

Table 6: Clinical manifestation in relation to $\operatorname{IgM}$ and $\operatorname{IgG}$ status

\begin{tabular}{|c|c|c|c|c|c|c|c|}
\hline \multirow[b]{2}{*}{$\begin{array}{l}\text { Clinical } \\
\text { Manifestation }\end{array}$} & \multirow[b]{2}{*}{$\begin{array}{l}\text { Patient's } \\
\text { Response }\end{array}$} & \multicolumn{3}{|c|}{ IgG } & \multicolumn{3}{|c|}{ IgM } \\
\hline & & $\begin{array}{c}\text { No Positive } \\
(\%)\end{array}$ & $\chi^{2}$ & P-value & $\begin{array}{c}\text { No Positive } \\
(\%)\end{array}$ & $\chi^{2}$ & P-value \\
\hline \multicolumn{8}{|l|}{ Headache } \\
\hline Yes & 119 & $39(32.8)$ & 0.156 & 0.693 & $28(23.5)$ & 0.138 & 0.710 \\
\hline No & 231 & $2(0.9)$ & & & $1(0.4)$ & & \\
\hline \multicolumn{8}{|l|}{ Fever } \\
\hline Yes & 328 & $37(11.3)$ & 0.172 & 0.458 & $25(7.6)$ & 0.132 & 0.716 \\
\hline No & 22 & $4(18.2)$ & & & $4(18.2)$ & & \\
\hline \multicolumn{8}{|l|}{ Weakness } \\
\hline Yes & 309 & $20(6.5)$ & 0.032 & 0.854 & $11(3.6)$ & 1.144 & 0.285 \\
\hline No & 41 & $21(51.2)$ & & & $18(43.9)$ & & \\
\hline \multicolumn{8}{|l|}{ Nausea } \\
\hline Yes & 166 & $16(9.6)$ & 0.307 & 0.580 & $9(5.4)$ & 0.234 & 0.628 \\
\hline No & 184 & $25(13.6)$ & & & $20(10.9)$ & & \\
\hline \multicolumn{8}{|l|}{ Diarrhoea } \\
\hline Yes & 119 & $5(4.2)$ & 0.710 & 0.710 & $10(8.4)$ & 0.003 & 0.954 \\
\hline No & 231 & $26(11.3)$ & & & $19(8.2)$ & & \\
\hline
\end{tabular}




\section{Discussion}

The most frequently recorded significant titre for the $\mathrm{O}$ antigen of $S$. typhi is $1 / 80$ and1/140 for the $\mathrm{H}$ antigen (Ohanu et al., 2019) and this was Page | 3624 adopted as the cut-off value for the interpretation of the result obtained. This agrees with a result from India (Aruni et al. (2014), which showed the significant titres above 1/80 for $\mathrm{O}$ antigen and $1 / 60$ for $H$ antigen for a diagnosis of Typhoid fever. However, it was in contrast with the study by Oyeyinka and Salimonu (1999) who recorded a titre of $<1 / 20$ for $S$. typhi $\mathrm{O}$ and $\mathrm{H}$ agglutination at Ibadan city. The variation in the widal reaction depends on the level to which Typhoid is endemic in a particular area, a fact which may change overtime (Punia et al., 2003) and the sanitary condition of that area. Other possible contributory factors include to the sharing of antigens by other serotypes in the Salmonellae family (Olopenia and King, 2000). Early use of antibiotics which can lead to low antibody titre and technical differences in the performance of the test.

The present study also found that titres of agglutinins to Salmonella typhi is higher than that of S. Papatyphi which is similar to other studies (Jeyakumari, et al., 2014). This indicated exposure to $S$. typhi is more among the population in this area. The rapid antibody assay used in this study is one out of several kits that have been modified to replace the widal reaction in the diagnosis of Typhoid fever. This is because the Widal test, which detects agglutinating antibodies in Patient serum against $\mathrm{O}$ and $\mathrm{H}$ antigen of $S$. typhi has been faced with a lot of controversy (Olopenia and King, 2000). In developed countries, diagnosis of typhoid fever during the acute phase of the illness by the Widal agglutination has largely been discontinued, especially in view of the low prevalence of the disease.

The Rapid kit used in this study was able to detected $\mathrm{IgG} / \mathrm{IgM}$ antibodies elicited in the patients in response to the antigens against of
Salmonella typhi in human blood/serum during Typhoid infection. The present study also revealed an increase in complement factor $\mathrm{C}_{3}$ levels in Typhoid positive patients as against those that were negative, this was in agreement with the work of Ghassan, (2006) who observed an increase in the levels of complement factors $\mathrm{C}_{3}$ and $\mathrm{C}_{4}$ among patients in Iraq. However, it was in contrast with the work of Kumar et al (1974) who reported the Complement C3 levels in Typhoid patients to be within normal range. The increase observed in this study is consistent with the fact that complement rises with most inflammatory response. The innate immune system plays an essential role in the early response to pathogenic bacteria and may be enough to control progression to disease in most subclinical infections. Also complement fixation on the bacterial surface could promote complement-receptor-facilitated uptake by phagocytes and activation of the complement cascade via the classical and alternative pathways which may eventually play a major role in resistance to many Gram-negative bacteria (Brown, 1991). Also, the significant association observed between the complement C3 and IgM reflects ongoing infections, since the IgM rises early in the acute phase of the disease (Boes, 2000).

The increase in the mean neutrophil count of Typhoid patients observed in this study was in agreement with the reports of Sarkinfada and Abubakar (2001) who reported an elevated neutrophil count in typhoid patients than healthy controls in Kano, but was in contrast with the findings of Emenuga et al. (2014) who observed a lower mean Neutrophil count in Typhoid patients than controls among Igbos in Enugu, Nigeria.

The elevated mean lymphocyte counts obtained in the Typhoid patient in this study was in agreement with the report of Emenuga et al. (2014) and Obeaghu, (2017) who also recorded a higher lymphocyte count in Typhoid patients than healthy individuals in Abia state, Nigeria. 
Page | 3625 lymphocytes (Lymphocytosis). Neutrophils play significant roles in the innate response and are crucial acute infection such as typhoid fever. It has also been reported that certain infectious agents may impair the bone marrow leading to its suppression or activation and are considered important mechanism in producing hematological changes (Khosla et al., 1995). Typhoid fever is known to be a multisystem disease that affects most organs including the bone marrow which leads to changes in PCV, neutrophils and lymphocytes.

Although a high number of the patients were positives for the agglutination titre in the Widal test, a few of them were detected positive for IgG and $\operatorname{IgM}$, This further support the reports by various authors that the Widal test is subjected to many faults such as reaction between antigens of other serotypes in the Salmonellae family, Furthermore patients may not demonstrate rise in antibody due to pre-exposure to $\mathrm{TAB}$ vaccines.

\section{Conclusions}

A total of $41(11.7 \%)$ and $29(8.3 \%)$ tested positive for IgG and IgM to S. typhi respectively of the 350 patients. It was found that 207 patients had Oantigen widal reaction titres $1 / 80$ and above for $S$. typhi out of which, 30 (14.5\%) and 22(22.6\%) were $\operatorname{IgG}$ and $\operatorname{IgM}$ positive respectively. The low positive recorded by the rapid assay confirm the report that the widal reaction results should by subjected to other confirmatory tests before a diagnosis is made. The neutrophil and lymphocyte counts were higher in the IgG and IgM positive patients as compared with those that were negative. These could serve as complimentary tools for diagnosis of typhoid disease. The mean complement C3 level was significantly elevated in the patients that were positive for typhoid IgM and $\operatorname{IgG}$ as compared with those that tested negative $(\mathrm{P}=0.000)$. None of the clinical features showed association with the disease indication that these are not sufficient and must be accompanied with laboratory analysis for conclusive diagnosis of typhoid fever.

\section{Conflict of Interest:}

The authors declare no conflicting interest in the publication No funding was obtained from any funding agency but the research was fully funded by the authors.

\section{References}

Abdool-Gaffar, M.S., Seedat, Y.K., Coovadia, Y.M, and Khan, Q. (1992). The white cell count in typhoid fever. Tropical Geography and Medicine. 44(1-2):23-7

Adabara N.U., Ezugwu B.U., Momoojimoh, A, Hashimu, Z. Damisa, D (2012). The prevalence and antibiotic susceptibility pattern of Salmonella among patients attending hospital in Minna, Nigeria. Advances in Preventive Medicine, 4(2): 3537

Aruni, I.S. (2014). Study of the baseline titre against Salmonella species amongst healthy individuals in thiruvanathapuram district of Kerala, South India, International Journal of Science and Technology, 20(1): 1380-1383.

Boes, M. (2000). Role of Natural and Immune IgM antibodies in immune responses. Molecular Immunology, 37(18):114-119.

Brown, E.J. (1991) Complement receptors and phagocytosis. Current Opinion in Immunology 3: 76-82.

Cheesbrough, M. (2006). District Laboratory practical in tropical countries part2, pp 229,314, 310-320, 324-327, 393394.Cambridge University press 
Crump, J.A., Luby, S.P., and Mintz, E.D. (2004). The global burden of typhoid fever. Journal of Clinical Infectious Disease, 82:46-53.

Elderman, R.A. and Levine, M.M. (1986) Page | 3626 Summary of international workshop on typhoidal fever. Journal of Infectious Diseases 8:329-349

Emenuga, V.N., Ureme, S.O., Ohanu, M.E, Ejiezie, F.E. and Nnabuchi, C.I. (2014). Some hematological and Biochemical profiles of Typhoid fever among Igbos in Nigeria. Indian Journal of Applied Research, 4(3):15-19

Ghassan, M. S. (2006) Immunological Study of Febrile Fever: Serum Sialic Acid, Immunoglobulin Levels (IgA, IgG and IgM), Complement Factors (C3 and $\mathrm{C} 4)$ in Patients with Typhoid Fever and Brucellosis The Iraqi Postgraduate Medical Journal 5(3):330 - 336

Ibekwe, A.C., Okonkwo I.O., Onunkwo, E. Donbraye, E. Babalola, E.T., Onoja, B.A. (2008). Baseline Salmonella agglutinin titres in apparently healthy freshmen in Awka, South Eastern Nigeria. Scientific Research and Essay, 3(9): 225-230.

Jeyakumari, D. Jaberlin, S.A., Gopal, R. (2014). A study of the baseline widal titre among healthy of rural population in Pondicherry. International journal of Medical Research and Health Sciences, 4 (2):223-235.

Khosla, S.N. Anad, A. and Singh, U. (1995). Hematological Profile in Typhoid fever. Tropical Doctor, 25:156-158.

Kumar: R.M., Murthy R.G.S, Venkatarman, M and Mohapatra, L.N. (1974) Immunological Study of Typhoid Immunoglobulins, C3 antibodies and Leukocytes migration inhibition in Patients with Typhoid fever and
Tab vaccinated individuals. Infection and Immunity 10:1219-1225

Mashi, K.N. (2001). Fighting infection using immune modulatory agents, Experimental Opinion of Biological Therapy, 40:641-653.

Mbuh, F.A., Galadima, M. and Ogbadu, L. (2003) Rate of coinfection with malaria parasites and Salmonella typhi in Zaria, Kaduna State, Nigeria. Annals of African Medicine, 2: 6467.

Naing, L. Winn, T. and Rushi, B.N. (2006). Practical issues in calculating the sample size for prevalence studies. Archives of Oroficial Studies, 1: 9-14

NPC (2013) National Population Commission. National and state population and housing table 12006; Retrieved March 10, 2013

Obeaghu, E.I. (2014). Changes in some haematological parameters in typhoid patients attending university Health services Okpara University, Department of Agriculture, Abia state, Nigeria. International Journal of Current Microbiology and Applied Sciences. 3(1):670-674.

Ochiai, R.L. Acosta, C.J. Danovara-Holiday, M.C Baiqing, D. Bhattacharya, S.K. Agtini, M.D. (2008). Typhoid study group, A study of typhoid in five Asian countries. Bulletin of World Health Organisation, 86:260-268.

Ohanu, M. E., Iroezindu,M. O., Maduakor,U., Onodugo,O. D. and Gugnani' H. C.(2019). Typhoid fever among febrile Nigerian patients: Prevalence, diagnostic performance of the Widal test and antibiotic multi-drug resistance. Malawi Medical Journal. 31(3): 184-192.

Olopenia L.A. and King AL. (2000). Widal agglutination test-100 years later: still 
plagued by controversy. Postgraduate Medical Journal, 76: 80-4

Olubuyide, I.O., Brown, N.M., Higginson, J. and Whicher, J.T. (1989) The value of C-reactive Page | 3627 protein in the diagnosis of intestinal perforation in typhoid fever Annals of Clinical Biochemistry 26: 246-248

Onuigbo, M.A. (1990) Diagnosis of typhoid fever in Nigeria: Misuse of the widal test. Trans Royal Society of Tropical Medicine and Hygiene 84 (1):129-131.PMID:2345914.

Oyeyinka, G.O. and Salimonu, L.S. (1999) Levels of complement components, immunoglobulins and acute phase proteins in plasma during aging in Nigeria. African Journal of Medicine and Medical Sciences 28(3-4):177-80

Passey, M. (1995). The new problem of typhoid fever in Papua, New Guinea: How do we deal with it? P.N.G. Medical Journal,;38:300

Punia, J.N. Joshi, R.M. Gupta, V. Avira, R.k. (2003). Determination of Baseline titres from Chandigarh. Indian Journal of Medical Microbiology.7(12): 2709-2711

Sarkinfada, A. and Abubakar, A.G. (2001). Leucocyte counts of Typhoid fever patients in Kano, Nigeria. NISEB Journal, 1(1):2225 .
Sheikh, A., Bhuiyan, M.S., Khanam, F., Chowdhury, F., Saha, A., Ahmed, D., Jamil, K.M., LaRocque, RC., Harris, J.B., Ahmad, M.M., Charles, R., Brooks, W.A., Calderwood, S.B., Cravioto, A., Ryan, E.T. and Qadri, F. (2009) Salmonella enterica serovar Typhi-specific immunoglobulin A antibody responses in plasma and antibody in lymphocyte supernatant specimens in Bangladeshi patients with suspected typhoid fever. Clinical and Vaccine Immunology 09/11: 1587-1594. doi: 10.1128/CVI.0031109.

Wain, J., Diep, T.S., Bay, P.V., Walsh, A.L., Vinh, H., Duong, N.M., Ho, V.A., Hien, T.T., Farrar, J., White, N.J., Parry, C.M. and Day, N.P. (2008) Specimens and culture media for the laboratory diagnosis of typhoid fever. Journal of infection in Developing Countries 2: 469-474.

World Health Ogarnisation (2003). Typhoid Vaccine (Initiative for Vaccine Research), WHO, Geneva, Switzerland. htt://www.int/vaccine research/disease/diarrhea/index7.html. Received April 4, 2005-Accepted April 4, 2005. 